Vol. 1 No. 1, Feb 2021, hlm. $103-110$

DOI: https://doi.org/10.33330/.v1i1.1054

Available online at https://jurnal.stmikroyal.ac.id/index.php/jutsi

\title{
PERANCANGAN ALAT ABSENSI MAHASISWA BERDASARKAN MATA KULIAH MENGGUNAKAN E-KTP BERBASIS NODEMCU
}

\author{
Siti Aminah ${ }^{1}$, Hambali $^{2 *}$, Rizky Fauziah Lubis ${ }^{2}$ \\ ${ }^{1}$ Mahasiswa Prodi Sistem Komputer, STMIK Royal \\ ${ }^{2}$ Prodi Sistem Informasi, STMIK Royal \\ *email: hambali.160886@gmail.com
}

\begin{abstract}
At present there are still many campuses or places of study, especially the Stmik Royal Kisaran campus, which does not utilize technology for student attendance based on courses, so it often manipulates attendance data. Manual attendance can cause lecturers or academics to record large amounts of student attendance data manually, and make the process ineffective and inefficient. Therefore, this study aims to discuss the Student Attendance System Design based on the course with NodeMCU-based IoT (Internet of Things) Using E-KTP. So that this research can facilitate the Stmik Royal Campus range for attendance systems present for students to be more effective and efficient and does not take much time. This system is integrated with the website so that when students attend learning activities in the room, data is automatically stored directly into the website database. Database processing on a website using MySQL with the PHP programming language. From several tests, many types of cards can be read by RFID Reader, because these cards have a frequency of $13.56 \mathrm{MHz}$. RFID Reader can also read RFID with a distance of 3-4 cm.
\end{abstract}

Keywords:Student Attendance, Nodemcu ESP8622, Website, Wifi, E-KTP, RFID.

\begin{abstract}
Abstrak:Saat ini masih banyak kampus atau tempat perkuliahan, terutama kampus STMIK Royal Kisaran, yang tidak memanfaatkan teknologi untuk kehadiran mahasiswa berdasarkan matakuliah, sehingga sering memanipulasi data kehadiran. Kehadiran manual dapat menyebabkan dosen atau pihak akademik merekam sejumlah besar data kehadiran mahasiswa secara manual, dan membuat proses tidak efektif dan tidak efisien. Oleh karena itu, penelitian ini bertujuan untuk membahas desain sistem kehadiran mahasiswa berdasarkan matakuliah dengan IoT (Internet of Things) Berbasis NodeMCU Menggunakan E-KTP. Sehingga penelitian ini dapat memfasilitasi Kampus STMIK Royal Kisaran untuk sistem absensi hadir bagi mahasiswa agar lebih efektif dan efisien dan tidak memakan banyak waktu. Sistem ini terintegrasi dengan situs web sehingga ketika mahasiswa hadir mengikuti kegiatan belajar di ruangan, data secara otomatis disimpan langsung ke dalam basis data situs web. Pemrosesan basis data pada situs web menggunakan MySQL dengan bahasa pemrograman PHP. Dari beberapa pengujian, banyak jenis kartu yang bisa terbaca oleh RFID Reader, dikarenakan kartu tersebut berfrekuensi 13.56MHz. RFID Reader juga dapat membaca kartu RFID dengan jarak $3-4 \mathrm{~cm}$.
\end{abstract}

Kata Kunci:Absensi Kehadiran Mahasiswa, NodeMCU ESP8622, Website, Wifi, E-KTP, RFID. 
Vol. 1 No. 1, Feb 2021, hlm. $103-110$

DOI: https://doi.org/10.33330/.v1i1.1054

Available online at https://jurnal.stmikroyal.ac.id/index.php/jutsi

\section{PENDAHULUAN}

Kemajuan elektronika sangat berkembang pesat saat ini, mulai dari peralatan yang dioperasikan secara manual hingga otomatis. Seperti alat absensi mata kuliah berbasis $E-K T P$ merupakan salah satu alat yang berguna bagi mahasiswa. Informasi yang terperinci mengenai kehadiran seorang mahasiswa dapat menentukan kedisiplinan dalam belajar. Merancang alat sistem absensi menggunakan RFID sebagai media pembaca identitas mahasiswa dan untuk menginput data absensinya [1]. Membuat absensi dengan menggunakan NodeMCU ESP8266 12e, serta menggunaka RFID dan aplikasi website. Perancangan alat yang dipakai dalam sistem ini berupa nodeMCU, $R F I D$ dan WEB karena NodeMCU digunakan sebagai alat pengendali yang dapat menghubungkan sistem dengan jaringan internet [2].

Teknologi RFID digunakan sebagai media pembaca inputan kartu identitas mahasiswa dalam memberi hasil data absensi mata kuliah, apabila mesin RFID atau kartu identitas tidak ada maka mahasiswa tidak dapat melakukan absensi. Selanjutnya $W E B$ digunakan untuk menampilkan data kehadiran mahasiswa secara otomatis, ketika $W E B$ tidak dipakai dalam pengisian absensi ini maka data kehadiran tidak dapat dilihat serta dicetak oleh staff admin STMIK Royal Kisaran. STMIK Royal Kisaran merupakan sebuah sekolah tinggi ilmu komputer yang berjalan di bidang pendidikan ilmu komputer.

Sistem absensi yang digunakan di STMIK Royal Kisaran masih menggunakan metode tanda tangan. Seiring berjalanya waktu, absensi secara manual ini menimbulkan masalah-masalah baru. STMIK Royal Kisaran adalah kampus perguruan tinggi dengan jurusan berbasis IT. Pendidikan tinggi yang berkarakter, professional, bertaqwa, beretika di tingkat nasional dan internasional dalam bidang komputer dan teknologi informasi. Adapun data mahasiswa per-tahunnya di STMIK Royal Kisaran dengan melihat tabel 1.

Tabel 1. Data Mahasiswa Per-Tahun Sistem Komputer

\begin{tabular}{|c|c|c|c|}
\hline Tahun & Jumlah & \multicolumn{2}{|c|}{ Jenis Kelamin } \\
\cline { 3 - 4 } Akademik & Mahasiswa & Laki-Laki & Perempuan \\
\hline $2011 / 2012$ & 55 & 46 & 9 \\
\hline $2012 / 2013$ & 84 & 76 & 8 \\
\hline $2013 / 2014$ & 122 & 108 & 14 \\
\hline $2014 / 2015$ & 117 & 104 & 13 \\
\hline $2015 / 2016$ & 107 & 102 & 5 \\
\hline $2016 / 2017$ & 101 & 93 & 8 \\
\hline $2017 / 2018$ & 102 & 93 & 9 \\
\hline $2018 / 2019$ & 103 & 91 & 14 \\
\hline $2019 / 2020$ & 100 & 86 & 12 \\
\hline
\end{tabular}


Vol. 1 No. 1, Feb 2021, hlm. $103-110$

DOI: https://doi.org/10.33330/.v1i1.1054

Available online at https://jurnal.stmikroyal.ac.id/index.php/jutsi

Tabel 2. Data Jumlah Mata Kuliah Sistem Komputer

\begin{tabular}{|c|c|c|}
\hline Tahun Akademik & Semester Ganjil & Semester Genap \\
\hline $2012-2020$ & 30 & 24 \\
\hline
\end{tabular}

Mahasiswa STMIK Royal pada umumnya sudah mempunyai E-KTP. E-KTP kartu identitas berkependudukan warga Negara Indonesia. E-KTP menandakan data-data seseorang dengan lengkap sesuai dengan tempat tinggal adapun data-data tersebut berupa nama, tanggal lahir, tempat tinggal, status dan lainnya. Sistem absensi yang dibangun berkaitan dengan E-KTP jadi mahasiswa STMIK ROYAL harus mempunyai E-KTP agar mahasiswa dapat melakukan absensi berdasarkan mata kuliah. Adapun beberapa mahasiswa STMIK Royal Kisaran yang tidak mempunyai $E$-KTP ataupun $E$ $K T P$ sedang mengalami perbaikan, jika ini terjadi mahasiswa bisa saja menggunakan KTM (Kartu Tanda Mahasiswa), KTM ini didapat melalui STMIK Royal setiap mahasiswa wajib mempunyai KTM untuk menandakan mereka sedang menjalani pendidikan di STMIK Royal Kisaran. Sistem yang akan dibangun tidak dapat mendektesi resi pengganti $E-K T P$.

Melalui adanya permasalahan tersebut, penulis tertarik untuk mengusulkan sistem absensi di STMIK Royal Kisaran menggunakan E-KTP dengan tampilan web berbasis NodeMCU, yang bertujuan untuk mempermudah staff STMIK Royal Kisaran dalam merekap laporan kehadiran mahasiswa-mahasiswa lainnya, dan membantu proses kehadiran, dimana sistem ini dapat mempercepat waktu pada saat melakukan absensi, serta dapat mengurangi tingkat kesalahan atau keakuratan data dengan sistem absensi sebelumnya. Melalui adanya sistem ini maka mahasiswa di STMIK Royal Kisaran akan lebih disiplin lagi dalam kehadiran. Cara kerja sistem ini dengan mengarahkan E-KTP dengan jarak $3 \mathrm{~cm}$ ke RFID, maka RFID tersebut akan terhubung ke web, kemudian laporan daftar hadir dapat dicetak sesuai dengan tanggal dan jam pada saat digunakan. Ketika $E-K T P$ dan KTM hilang atau ketinggalan di rumah maka segera melapor ke bagian staff admin, supaya menginputkan daftar hadirnya ke sistem akan di beri dispensasi.

Apabila kejadian ini berturut-turut sampai 3 kali dalam sebulan, maka tidak ada lagi dispensasi bagi mahasiswa yang meninggalkan $E-K T P$, dan harus dijeput kembali supaya tidak menjadi kebiasaan bagi mahasiswa-mahasiswa lainnya. Jika terjadi yang namanya titip absensi, maka staff admin akan memberikan kebijakan keras kepada mahasiswa yang melanggar peraturan. Ketika seorang mahasiswa menggunakan E-KTP yang belum terdaftar, maka alarm pada mesin absensi akan berbunyi sebanyak 3 kali , LED kedip 3 kali dan tampil di LCD, Ketika seorang mahasiswa menggunakan E-KTP yang sudah melakukan absensi, maka alarm pada mesin absensi akan berbunyi sebanyak 2 kali dan LED kedip 2 kali dan tampil di LCD.

\section{METODE}

Metode penelitian yang digunakan metode deskriptif. Adapun tahapan-tahapan yang dilakukan dalam metode diskriptif diantaranya : (1) Penentuan alat atau modul yang digunakan dalam penelitian, diantaranya NodeMCU Esp8266, RFID, Buzzer, 
Vol. 1 No. 1, Feb 2021, hlm. $103-110$

DOI: https://doi.org/10.33330/.v1i1.1054

Available online at https://jurnal.stmikroyal.ac.id/index.php/jutsi

Acces Point, Komputer., (2) Pengujian sistem kerja dari setiap modul., (3) Penggabungan sistem kerja dari tiap modul., (4) Pembuatan program dari tiap., (5) modul., (6) Implementasi.

Adapun alur dari metode diskriptif di tunjukan pada gambar 1.

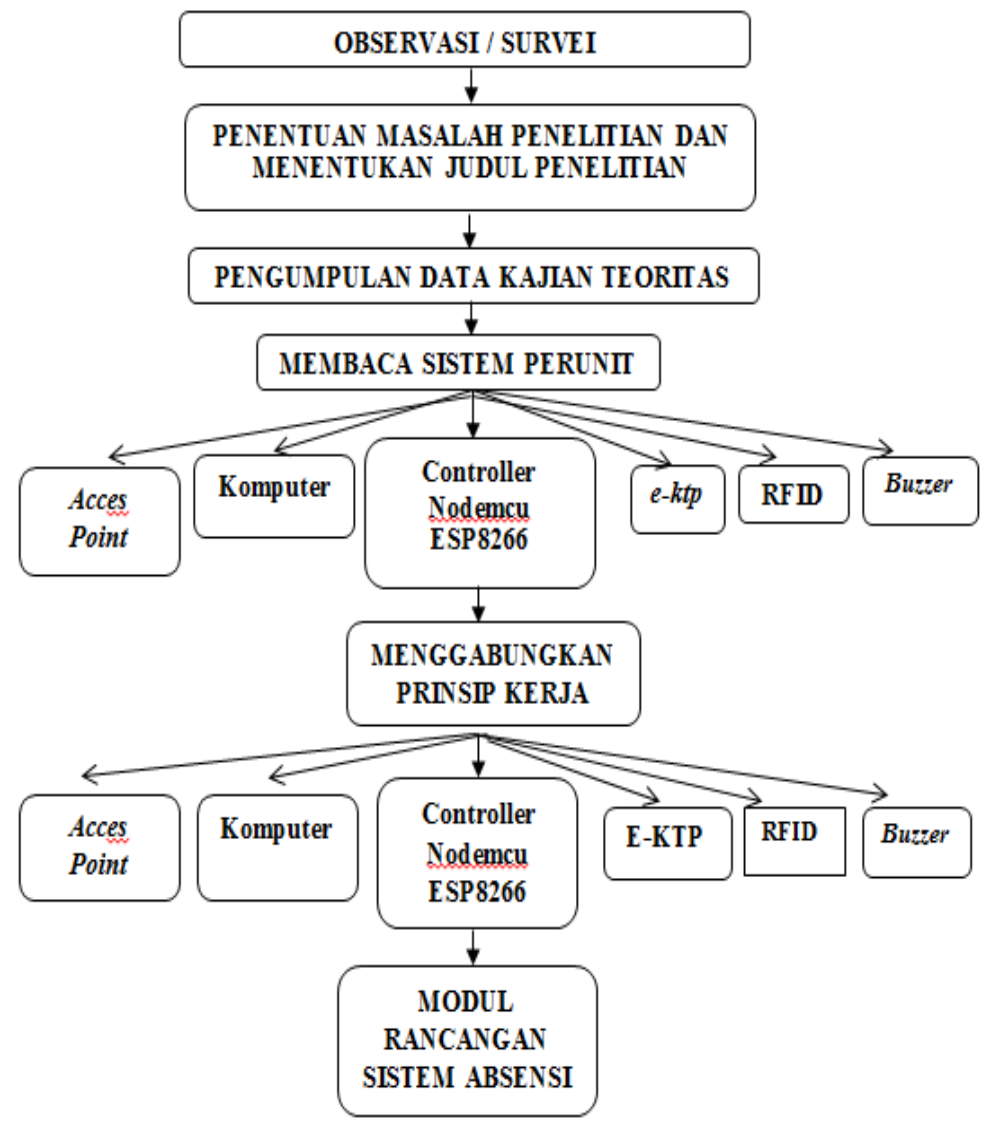

Gambar 1. Metode Diskripsi Penelitian Perancangan Sistem Absensi.

Dari blok diagram diatas perangkat-perangkat utama yang dibutuhkan, diantaranya dapat dijelaskan sebagai berikut.

\section{NodeMCU ESP8266}

NodeMCU ESP8266 adalah sebuah modul elektronika yang dirancang dan disusun secara terstruktur serta dapat menghubungkan IC microcontroller dengan sebuah jaringan lokal maupuan internet melalui media transmisi nirkabel / Wi-Fi. IC ESP8266 yang diletak kedalam papan elektronika/PCB NodeMCU menggunakan bahasa pemograman berbasis opensource yang ada di platform IoT [3].

Dalam pengembangan kit/module yang menggunakan sketcth program menggunakan aplikasi arduino IDE. Pengembangan kit/module ini didasarkan pada modul NodeMCU ESP8266, yang saling terhubung satu sama lain antara GPIO, PWM (Pulse Width Modulation), IIC , 1-Wire dan ADC semua dalam satu papan elektronika / PCB. 
Vol. 1 No. 1, Feb 2021, hlm. $103-110$

DOI: https://doi.org/10.33330/.v1i1.1054

Available online at https://jurnal.stmikroyal.ac.id/index.php/jutsi

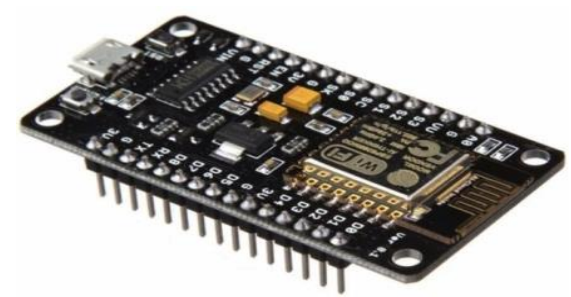

Gambar 2. NodeMCU ESP8266

Selain itu software pendukung NodeMCU bisa mengunakan firmware programmer untuk proses flashing firmware untuk dapat mengembangkan firmware modul NodeMCU ESP8266 ini, perusahaan espressif chinese manufacturer (ECM) telah menyediakan Software Development Kit (SDK) secara lengkap.

\section{RFID (Radio Frequency Identification)}

Mengenai teknologi RFID adalah sebuah teknologi hasil rintisan oleh seorang utusan mata-mata dari negara Rusia yang dahulunya negara Uni Soviet. Berhasil menemukan sebuah sistem pengiriman gelombang radio melalui informasi suara/audio. Gelombang tersebut menimbulkan getaran diagfragma kemudian dibentuk menjadi sebuah memodulasi gelombang radio terpantul [4]. Meskipun alat ini bukan sebuah asal mula dari RFID. Namun dianggap sebagai pendahulu teknologi dari RFID. Selain itu, Perangkat RFID yang menjadi asal usul sistem RFID modern adalah Perangkat Mario Cardullo, karena menggunakan transponder radio pasif menggunakan memory.

Radio Frequency Identification (RFID) yaitu sebuah modul elektronika yang berfungsi untuk menggambarkan suatu teknologi yang mengirimkan data identitas dalam bentuk nomor seri yang unik dari suatu benda/kartu yang memiliki chip tanpa harus menggunakan kabel. Teknologi Radio Frequency Identification (RFID) menggunakan sistem identifikasi dengan gelombang radio.

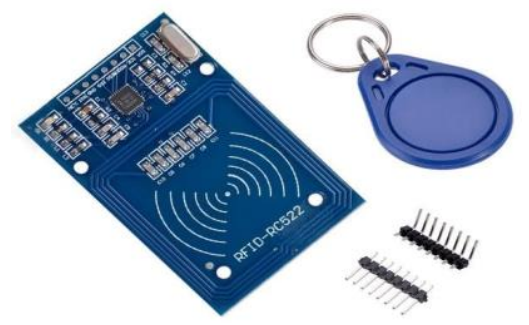

Gambar 3. RFID

\section{E-KTP (Transponder)}

E-KTP adalah sebuah kartu identitas penduduk yang wajib di miliki semua warga negara Republik Indonesia. Setiap orang harus mempunyai kartu tanda penduduk seperti E-KTP. E-KTP akan memberikan sinyal inputan kepada $R F I D$ karena memiliki chip yang dapat melakukan sebuah pemrosesan yang sedang diproses sesuai dengan data nomor seri unik yang ada pada $E-K T P$ yang dimiliki. E-KTP akan memberikan sebua inputan terhadap $R F I D$ dengan cara men-tap kan kartu $E-K T P$. 
Vol. 1 No. 1, Feb 2021, hlm. $103-110$

DOI: https://doi.org/10.33330/.v1i1.1054

Available online at https://jurnal.stmikroyal.ac.id/index.php/jutsi

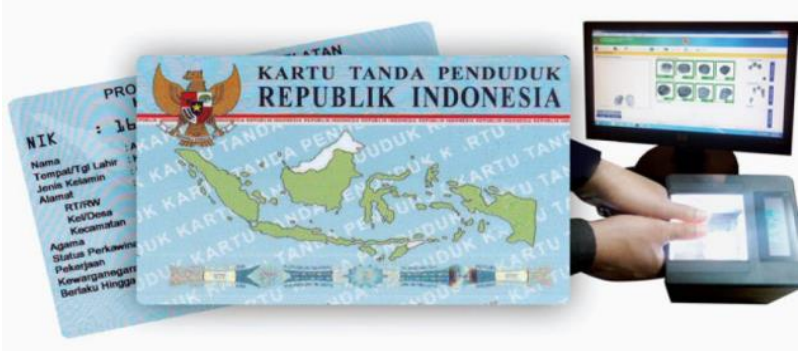

Gambar 4. E-KTP Elektronik

\section{Software Arduino IDE}

Aplikasi Arduino IDE (Integreted Development Environment) adalah sebuah aplikasi / software untuk membuat program terstruktur agar dapat menjadi pengendali IC Microcontroller yang bersifat open source, Software ini berasal dari platform wiring, dibuat dan digunakan untuk memudahkan penggunaan elektronik dalam berbagai bidang, hardware-nya yang digunakan beberapa macam seperti salah satu hadware vital prosesor Atmel AVR dan software-nya menggunakan bahasa pemrograman \#C yang sederhana dan tools yang lengkap, sehingga teknologi Arduino mudah dipelajari oleh pemula elektronika [5].

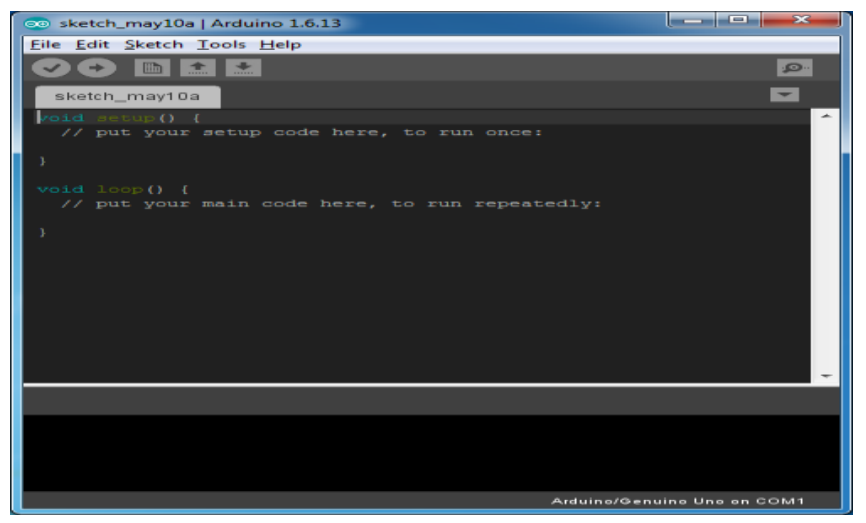

Gambar 5. Tampilan Software Arduino IDE

\section{Kabel Jumper}

Kabel jumper atau media penghantar aliran listrik adalah sebuah kabel yang memiliki ukuran panjang tertentu dan pangkal ujung tertentu seperti female, male, female-male. Kabel ini digunakan sebagai media untuk menghubungkan antara komponen yang satu dengan komponen elektronika lainnya pada pin yang ada di breadboard sehingga terhubung dengan arus listrik dan terbentuk rangkaian elektronika yang terstruktur. 
Vol. 1 No. 1, Feb 2021, hlm. $103-110$

DOI: https://doi.org/10.33330/.v1i1.1054

Available online at https://jurnal.stmikroyal.ac.id/index.php/jutsi

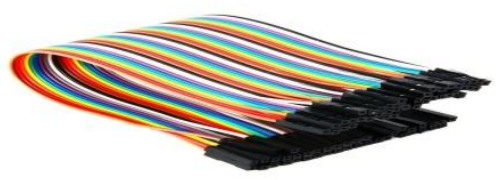

Gambar 6. Kabel Jumper

\section{Adaptor}

Adaptor merupakan sebuah rangkaian power supply yang sudah menjadi modul serta digunakan secara langsung tanpa merakit dari awal. Fungsi adaptor adalah untuk mengubah tegangan dari AC biasanya PLN rumah tangga 220 Volt menjadi DC yang biasanya 5 Volt. Adaptor juga sudah banyak digunakan pada catu daya radio, pesawat televisi mini dan perangkat elektronik lainnya. Harga pasaran untuk sebuah adaptor bisa tergolong cukup murah.

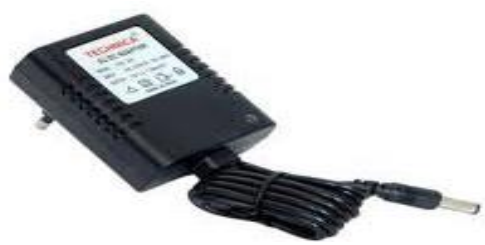

Gambar 7. Adaptor

\section{Buzzer}

Buzzer atau Alarm adalah sebuah elektronika yang mampu menghasilkan bunyi. Pada umumnya, Komponen buzzer sudah banyak digunakan dalam rangkaian alarm anti-maling, alarm pada absensi, bel rumah, dan perangkat peringatan bahaya lainnya.

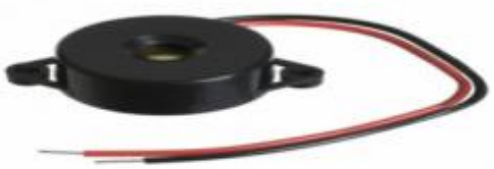

Gambar 8. Buzzer

\section{HASIL DAN PEMBAHASAN}

Setelah implementasi dan pengujian dilakukan, maka selanjutnya menganalisa hasil dari penelitian, dimana pada penelitian ini penulis mendapatkan beberapa poin yang dapat dijabarkan berdasarakan analisa implementasi, berikut ini hasil analisa bedasarkan hasil penelitian : (1) Penelitian telah dilakukan berdasarkan pada analisa perancangan dan masalah yang di jabarkan di bab sebelumnya, penelitian menghasilkan output berupa sebuah sistem absensi mahasiswa STMIK Royal Kisaran menggunakan E-KTP yang hasil pelaporan absensi menggunakan website., (2) Sistem website yang dihasilkan berjalan pada sistem operasi windows dan web browser yang stabil seperti google chorme , Mozilla firefox, dan lain-lain., (3) Penanganan absensi mahasiswa STMIK Royal Kisaran menggunakan E-KTP., (4) Hasil penelitian dapat dikembangkan 
dan disesuaikan dengan penelitian baru untuk menambah fitur dan manfaat dari penggunaan aplikasi.

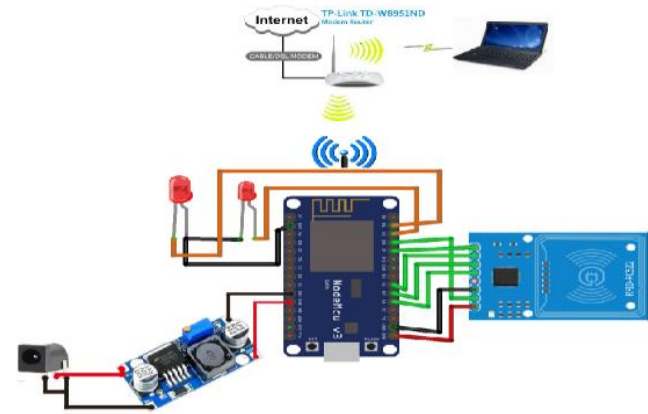

Gambar 9. Rangkaian Keseluruhan Sistem Otomatisasi

\section{SIMPULAN}

Berdasarkan uraian pada bab-bab sebelumnya dan hasil penelitian, dapat diambil kesimpulan sebagai berikut : (1) Merancang dan membuat sistem absensi yang terintegrasi oleh website telah berhasil di lakukan., (2) Proses membuat laporan absensi bisa dilihat melalui website oleh pihak admin STMIK Royal Kisaran berjalan dengan baik., (3) Sistem absensi mahasiswa berdasarkan matakuliah dengan E-KTP sangat efektif untuk menghindari manipulasi data absensi mahasiswa.

\section{DAFTAR PUSTAKA}

[1] Subiantoro and Sardiarinto, "Perancangan Sistem Absensi Pegawai Berbasis Web," J. Swabumi, vol. 6, no. 2, pp. 184-189, 2018.

[2] A. K. Putri, S. Widodo, and A. Hasan, "Sistem Pencatatan Kehadiran Mahasiswa Dan Dosen Serta Perhitungan Kompensasi Di Program Studi Teknik Telekomunikasi Politeknik Negeri Semarang Menggunakan Rfid Dan Dikirim Melalui SMS Gateway," Techno (Jurnal Fak. Tek. Univ. Muhammadiyah Purwokerto), vol. 17, no. 1, pp. 48-055, 2017,

[3] M. R. Hidayat, C. Christiono, and B. S. Sapudin, "Perancangan Sistem Keamanan Rumah Berbasis Iot Dengan Nodemcu Esp8266 Menggunakan Sensor Pir Hc-Sr501 Dan Sensor Smoke Detector," Kilat, Vol. 7, No. 2, Pp. 139-148, 2018, doi: 10.33322/kilat.v7i2.357.

[4] J. Coreit et al., "Perancangan Sistem Absensi Kehadiran Perkuliahan dengan Menggunakan Radio Frequency Identification ( RFId )," vol. 1, no. 2, pp. 44-49, 2015.

[5] A. R. Fikriyah, Lulu, "Sistem Kontrol Pendingin Ruangan Menggunakan Arduino Web Server Dan Embedded Fuzzy Logic Di Pt. Inoac Polytechno Indonesia," J. Inform. SIMANTIK Vol. 3 No. 1 Maret 2018, vol. 3, no. 1, pp. 123, 2007. 